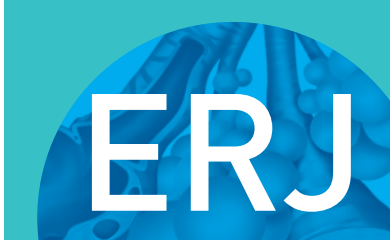

open research

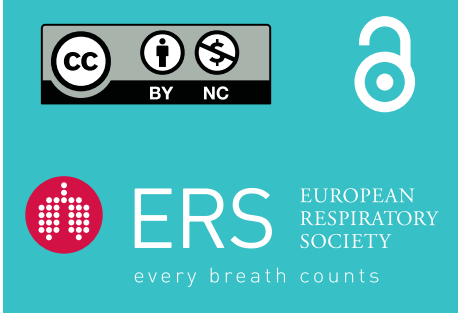

\section{The effect of physical activity on asthma incidence over 10 years: population- based study}

\section{To the Editor:}

Asthma remains a common disease around the world, with global estimates indicating that $4.3 \%$ of adults have doctor-diagnosed asthma [1]. Physical activity has been found to improve asthma outcomes in adults with asthma [2,3]. While it has been hypothesised that physical activity could also reduce asthma incidence through a variety of mechanisms, studies to date have provided mixed results. Some studies find that physical activity reduces the incidence of asthma $[4,5]$, yet others find no evidence for a reduction in risk $[6,7]$. These inconsistent findings could be partly attributed to variation in the definition of incident asthma, which is mostly restricted to self-reported asthma outcomes. In this analysis, we investigated the association between (frequency and duration of) vigorous physical activity and asthma incidence over 10 years, using the European Community Respiratory Health Survey (ECRHS), considering multiple asthma-related outcomes in an initially asthma-free population.

ECRHS is a multicentre cohort involving 46 centres in 25 countries in Europe and Australia [8]. From a random sample in ECRHS I, participants (originally 20-44 years of age) completed questionnaires and a battery of tests twice more at 10-year intervals. The present analysis uses data from ECRHS II (42 to 57 years of age) and ECHRS III (54 to 68 years of age), as physical activity data were not collected in ECRHS I. ECRHS II involved 10217 participants. Of these, we excluded participants who reported: 1) "ever asthma" in ECRHS I or II $(\mathrm{n}=1895)$; 2) wheeze in the previous 12 months at ECRHS I or II $(\mathrm{n}=2328)$; or 3$)$ an asthma attack prior to ECRHS I or ECHRS II $(\mathrm{n}=70)$. Additionally, 2421 participants were lost to follow-up, leaving 3503 participants for analysis. Ethics approval was gained by each centre.

The ECRHS II and ECRHS III questionnaires included items regarding vigorous physical activity during leisure time, in addition to questions regarding the diagnosis of respiratory diseases, respiratory symptoms, medications taken, occupation, smoking and other socio-demographic factors. The responses from the questions "How often do you usually exercise so much that you get out of breath or sweat?" and "How many hours a week do you usually exercise so much that you get out of breath or sweat?" were categorised by frequency (once a month or less, $1-3$ times per week, $\geqslant 4$ times per week) and duration (0 to $30 \mathrm{~min}, 1$ to $3 \mathrm{~h}, \geqslant 4 \mathrm{~h}$ per week), respectively. Participants reporting at least $1 \mathrm{~h}$ of vigorous activity across two to three incidences per week were classified as "vigorously active", and participants reporting less for either question were classified as "not vigorously active" [9]. This classification was applied across ECRHS II and ECRHS III data and used to create the categories of "consistently vigorously active", "becoming vigorously inactive", "becoming vigorously active" and "consistently not vigorously active" as a "change in vigorous activity status" variable.

Asthma incidence was assessed using several outcomes at ECRHS III. Firstly, current asthma was deemed present if participants responded positively to the question "Have you had wheezing or whistling in your chest at any time in the last 12 months" and/or "Are you currently taking any medicines including inhalers, aerosols or tablets for asthma" [10]. Secondly, asthma-like symptoms were deemed present with more than three positive responses to questions regarding 12-month symptoms of: 1) wheeze, 2) wheeze

$@$ ERSpublications

Although there are many health benefits from being active, there was no benefit observed in this study from vigorous physical activity in reducing the risk of asthma onset in middle-aged adults https://bit.ly/3bEtHDn

Cite this article as: Russell MA, Dharmage S, Fuertes E, et al. The effect of physical activity on asthma incidence over 10 years: population-based study. ERJ Open Res 2021; 7: 00970-2020 [https:// doi.org/10.1183/23120541.00970-2020].

Copyright $\odot$ The authors 2021. This version is distributed under the terms of the Creative Commons Attribution NonCommercial Licence 4.0. For commercial reproduction rights and permissions contact permissions@ersnet.org 
TABLE 1 Association between European Community Respiratory Health Survey (ECRHS) II vigorous activity status, frequency and duration, change in vigorous activity status and ECRHS III current asthma, asthma-like symptoms, and bronchodilator reversibility in middle-aged adults

\begin{tabular}{|c|c|c|c|c|c|c|}
\hline & $\begin{array}{l}\text { Current asthma at } \\
\text { ECRHS III n }(\%)\end{array}$ & $\begin{array}{c}\text { Risk of current } \\
\text { asthma, adjusted } \\
\text { analyses }{ }^{\#}(95 \% \mathrm{Cl})\end{array}$ & $\begin{array}{c}\text { More than three } \\
\text { asthma-like symptoms } \\
\text { at ECRHS III (\%) }\end{array}$ & $\begin{array}{c}\text { Risk of asthma-like } \\
\text { symptoms, } \\
\text { adjusted }(95 \% \mathrm{CI})^{\#}\end{array}$ & $\begin{array}{l}\text { Bronchodilator } \\
\text { reversibility present } \\
\text { at ECRHS III } \mathbf{n}(\%)\end{array}$ & $\begin{array}{l}\text { Risk of bronchodilator } \\
\text { reversibility, adjusted } \\
\text { analyses }{ }^{\#}(95 \% \mathrm{CI})\end{array}$ \\
\hline Subjects $n$ & 3129 & 2757 & 3057 & 2695 & 2451 & 2148 \\
\hline \multicolumn{7}{|l|}{ Activity status } \\
\hline Not vigorously active & 182 (8.9) & 1.00 & $54(2.8)$ & 1.00 & $38(2.5)$ & 1.00 \\
\hline Vigorously active & $102(8.4)$ & $0.96(0.75-1.23)$ & $22(1.9)$ & $0.71(0.42-1.18)$ & $21(2.2)$ & $0.82(0.46-1.47)$ \\
\hline \multicolumn{7}{|l|}{ Frequency of vigorous activity } \\
\hline Once a month or less & $120(9.1)$ & 1.00 & $36(2.8)$ & 1.00 & $25(2.6)$ & 1.00 \\
\hline 1-3 times per week & $120(7.7)$ & $0.94(0.73-1.22)$ & $31(2.1)$ & $0.78(0.48-1.28)$ & $29(2.4)$ & $0.86(0.49-1.50)$ \\
\hline$\geqslant 4$ times per week & 45 (10.7) & $1.14(0.82-1.63)$ & $10(2.5)$ & $0.93(0.45-1.93)$ & 6 (1.9) & $0.67(0.25-1.76)$ \\
\hline \multicolumn{7}{|l|}{ Amount of vigorous activity } \\
\hline 0-30 min per week & $132(9.8)$ & 1.00 & $39(3.0)$ & 1.00 & $28(2.8)$ & 1.00 \\
\hline 1-3 h per week & $105(7.4)$ & $0.82(0.63-1.07)$ & $30(2.2)$ & $0.79(0.48-1.30)$ & $24(2.2)$ & $0.74(0.42-1.31)$ \\
\hline$\geqslant 4 \mathrm{~h}$ per week & $47(9.5)$ & $1.00(0.71-1.42)$ & $7(1.5)$ & $0.49(0.21-1.17)$ & $7(1.8)$ & $0.66(0.27-1.61)$ \\
\hline \multicolumn{7}{|l|}{$\begin{array}{l}\text { Change in vigorous activity from } \\
\text { ECRHS II to ECRHS III }\end{array}$} \\
\hline Consistently not vigorously active & $123(9.1)$ & 1.00 & $43(3.2)$ & 1.00 & $29(2.8)$ & 1.00 \\
\hline Becoming vigorously inactive & $54(8.7)$ & $1.00(0.70-1.43)$ & $11(1.9)$ & $0.83(0.34-1.35)$ & $9(1.9)$ & $0.96(0.44-2.08)$ \\
\hline Becoming vigorously active & $41(9.1)$ & $1.11(0.80-1.54)$ & $11(2.4)$ & $0.68(0.42-1.61)$ & $10(2.8)$ & $0.83(0.39-1.78)$ \\
\hline Consistently not vigorously active & $60(8.5)$ & $1.01(0.73-1.41)$ & $11(1.6)$ & $0.50(0.24-1.03)$ & $11(1.9)$ & $0.64(0.29-1.42)$ \\
\hline
\end{tabular}


with breathlessness, 3) wheeze without a cold, 4) nocturnal chest tightness, 5) nocturnal shortness of breath, 6) nocturnal attack of coughing, 7) asthma attack and 8) current asthma medications [11]. Bronchodilator reversibility was deemed present when there was an increase or decrease in forced expiratory volume in $1 \mathrm{~s}\left(\mathrm{FEV}_{1}\right)$ of $12 \%$ and $>200 \mathrm{~mL}$ from baseline [12]. This change is accepted as being consistent with asthma in those with respiratory symptoms [12].

We also utilised ECRHS I data on sex, age and age at completion of education $(<17,17-20, \geqslant 21$ years) and ECRHS II data on occupation (categorised according to the International Standard Classification of Occupations- 88 code [13]) and objectively measured weight and height, from which we derived body mass index (BMI). ECRHS II smoking data were collected across multiple questions and categorised as never-smoker, ex-smoker and current-smoker.

Associations between the physical activity measurements (ECRHS II vigorous activity status, frequency and duration, change in vigorous activity status during follow-up) were examined for each asthma outcome (current asthma, asthma-like symptoms, bronchodilator reversibility) using modified Poisson regression [14]. Age, sex, age at the completion of education, BMI, smoking and occupation at ECRHS II were included as covariates, as they were identified as potential confounders a priori. Centre clustering was taken into account using robust standard errors, and interactions between physical activity and age, sex, $\mathrm{BMI}$ and smoking were considered.

We conducted three sensitivity analyses: 1) to account for potential residual confounding we repeated analyses with adjustment for heart disease at ECRHS III, available in a subsample $(\mathrm{n}=2195)$; 2$)$ to investigate the potential attenuating effects of asthma medications, we repeated the analyses with bronchodilator reversibility as the outcome excluding those taking asthma medications at ECRHS III; and 3) to investigate heterogeneity across regions, we conducted a random-effects meta-analysis. Stata ver16 (StataCorp, College Station, TX, USA) was used.

The participants included in this analysis were similar to those eligible with regard to age, sex, physical activity and BMI. However, those included were less likely to be current smokers (21\% versus $27 \%$ ) and more likely to have completed their education after 21 years of age (48\% versus $41 \%$ ) at ECRHS II than those lost to follow-up ( $40 \%$ of the ECRHS II cohort).

The average age of the 3503 participants at ECRHS II was 43 years (SD 7.0), 52\% were female and average BMI was 25.1 (SD 3.9) $\mathrm{kg} \cdot \mathrm{m}^{-2}$. The majority were never-smokers (48\%) with $31 \%$ being ex-smokers and $21 \%$ current smokers. Over half (52\%) completed their education by 21 years of age, and $37 \%$ were working in management/professional fields. The majority of participants were classified as not vigorously active $(63 \%)$ at ECRHS II. Almost half of participants $(43 \%)$ were not vigorously active at both time points. At ECRHS III, 9\% of participants had current asthma, 2\% reported more than three asthma-like symptoms and $2 \%$ had a positive bronchodilator response.

There was little association between the vigorous physical activity measures and asthma outcomes (table 1). No differences were observed in the sensitivity analyses, and no interactions were found with the potential effect modifiers investigated (results not shown).

In this population of initially asthma-free middle-aged adults, we found little association between vigorous physical activity and the onset of asthma measures over a 10-year period. These results are consistent with some previous research investigating the effect of physical activity on asthma incidence [6,7]. Of the two studies that found a beneficial effect of physical activity on asthma incidence, one appeared not to adjust for relevant confounders, such as age and smoking [4], and the other study used lighter physical activity as the exposure [5]. The lack of observable beneficial associations from physical activity in our study may be because of insufficient statistical power, that only less vigorous physical activity protects against asthma incidence, or that there is no benefit from physical activity in regard to asthma incidence.

The strengths of this study were the long-term follow-up, reduction in asthma misclassification by combining self-report with objective measurements and inclusion of several sensitivity analyses to minimise other potential biases. Study weaknesses include loss to follow-up and the utilisation of self-reported (instead of objective) physical activity measures; self-report of physical activity can impact validity due to an individual's propensity to overestimate physical activity levels. Additionally, bronchodilator reversibility, although a measure of asthma, can also be present with other respiratory diseases [15]. In conclusion, although multiple health benefits from physical activity are known, we did not find evidence that participating in vigorous physical activity during leisure time reduced the risk of asthma developing in adults.

Melissa Anne Russell $\oplus^{1,2}$, Shyamali Dharmage ${ }^{1,2}$, Elaine Fuertes ${ }^{3}$, Alessandro Marcon $\oplus^{4}$, Anne-Elie Carsin ${ }^{5,6,7,8}$, Silvia Pascual Erquicia ${ }^{9}$, Joachim Heinrich ${ }^{1,10}$, Ane Johannessen ${ }^{11}$, 
Michael J. Abramson $\oplus^{12}$, Andre F.S. Amaral $\oplus^{3}$, Isa Cerveri ${ }^{13}$, Pascal Demoly $\oplus^{14,15}$, Vanessa Garcia-Larsen $\oplus^{16}$, Deborah Jarvis $\oplus^{3,17}$, Jesus Martinez-Moratalla ${ }^{18,19}$, Dennis Nowak $\oplus^{10}$, Leopoldo Palacios-Gomez ${ }^{20}$, Giulia Squillacioti ${ }^{21}$, Wasif Raza $^{22}$, Margareta Emtner ${ }^{23}$ and Judith Garcia-Aymerich $\oplus^{5,7,8}$

${ }^{1}$ Allergy and Lung Health Unit, Melbourne School of Population and Global Health, The University of Melbourne, Melbourne, Australia. ${ }^{2}$ Gastro and Food Allergy Group, Murdoch Children's Research Institute, Melbourne, Australia. ${ }^{3}$ National Heart and Lung Institute, Imperial College London, London, UK. ${ }^{4}$ Unit of Epidemiology and Medical Statistics, Department of Diagnostics and Public Health, University of Verona, Verona, Italy. ${ }^{5}$ Barcelona Institute of Global Health (ISGlobal), Barcelona, Spain. ${ }^{6}$ IMIM-Hospital del Mar, Barcelona, Spain. ${ }^{7}$ CIBER Epidemiologia y Salud Publica, Barcelona, Spain. ${ }^{8}$ Universitat Pompeu Fabra (UPF), Barcelona, Spain. ${ }^{9}$ Respiratory Department, Galdakao Hospital, OSI Barrualde-Galdakao, Biscay, Spain. ${ }^{10}$ Institute and Clinic for Occupational, Social and Environmental Medicine, University Hospital, LMU Munich, Comprehensive Pneumology Center (CPC) Munich, Member DZL, German Center for Lung Research, Munich, Germany. ${ }^{11}$ Centre for International Health, Department of Global Public Health and Primary Care, University of Bergen (NO), Bergen, Norway. ${ }^{12}$ School of Public Health \& Preventive Medicine, Monash University, Melbourne, Australia. ${ }^{13}$ Division of Respiratory Diseases, IRCCS Policlinico San Matteo, University of Pavia, Pavia, Italy. ${ }^{14}$ Département de Pneumologie et addictologie, Hôpital Arnaud de Villeneuve, University Hospital of Montpellier, Montpellier, France. ${ }^{15}$ INSERM UMR-S 1136, IPLESP, Sorbonne Université, Paris, France. ${ }^{16}$ Dept of International Health, The Johns Hopkins Bloomberg School of Public Health, Baltimore, USA. ${ }^{17}$ MRCPHE Centre for Environment and Health, Imperial College London, London, UK. ${ }^{18}$ Servicio de Neumología del Complejo Hospitalario Universitario de Albacete, Albacete, Spain. ${ }^{19}$ Facultad de Medicina de Albacete, Universidad de Castilla - La Mancha, Albacete, Spain. ${ }^{20}$ El Torrejón Health Centre, Andalusian Health Service, Huelva, Spain. ${ }^{21}$ Dept of Public Health and Pediatrics, University of Turin, Turin, Italy. ${ }^{22}$ Dept of Public Health and Clinical Medicine, Section of Sustainable Health, Umeå University, Umea, Sweden. ${ }^{23}$ Dept of Medical Sciences: Respiratory, Allergy and Sleep Research, Uppsala University, Uppsala, Sweden.

Correspondence: Melissa Russell, The University of Melbourne, 207 Bouverie St, Carlton, Victoria 3010, Australia. E-mail: melissar@unimelb.edu.au

Received: 22 Dec 2020 | Accepted: 24 Dec 2020

Data availability: Data not available. The authors do not have permission to share data.

Conflict of interest: M.A. Russell has nothing to disclose. S. Dharmage has nothing to disclose. E. Fuertes has nothing to disclose. A. Marcon has nothing to disclose. A-E. Carsin has nothing to disclose. S. Pascual Erquicia has nothing to disclose. J. Heinrich has nothing to disclose. A. Johannessen has nothing to disclose. M.J. Abramson has nothing to disclose. A.F.S. Amaral has nothing to disclose. I. Cerveri has nothing to disclose. P. Demoly reports board fees from Chiesi, IQVIA, Ménarini and Sanofi; board and speaker bureau fees from AstraZeneca, Bausch \& Lomb and ThermoFisher Scientific; and speaker fees from Mylan and Novartis, all outside the submitted work. V. Garcia-Larsen has nothing to disclose. D. Jarvis has nothing to disclose. J. Martinez-Moratalla has nothing to disclose. D. Nowak has nothing to disclose. L. Palacios-Gómez has nothing to disclose. G. Squillacioti has nothing to disclose. W. Raza has nothing to disclose. M. Emtner has nothing to disclose. J. Garcia-Aymerich has nothing to disclose.

Support statement: This study was supported by Fondazione Cassa di Risparmio di Verona Vicenza Belluno e Ancona; Comissió Interdepartamental de Recerca i Innovació Tecnològica grant 1997 SGR 00079; Deutsche Forschungsgemeinschaft grants HE 3294/10-1, MA 711/6-1 and NO 262/7-1; National Health and Medical Research Council grant 92091; the Belgian Federal Science Policy Office; Estonian Science Foundation grant 1088; the Asthma Foundation of Victoria; Bundesministerium für Forschung und Technologie; The Swiss The Federal Office of Public Health; Allen and Hanbury's; Wellcome Trust grant 084703MA; Helse Vest grant 911631; Ministre delegué de la santé; CNMATS; CNMRT grants 90MR/10 and 91AF/6; Háskóli Íslands; the canton Lung Leagues of Basel Stadt/Basel, Landschaft, Geneva, Ticino, Valais and Zurich; INSERM Université Bordeaux segalen grant U897; Comite Scientifique AGIRadom 2011; Ministère de la Santé Programme Hospitalier de Recherche Clinique (PHRC) national 2010; RNSP, France; Agence Nationale de la Santé, Région Ile de France, domaine d'intérêt majeur (DIM); the Bergen Medical Research Foundation; Medical Research Council grant 92091; a Vasterbotten County Council ALF grant; Dirección Regional de Salud Pública (Consejería de Sanidad del Principado de Asturias); Lungenliga Schweiz; Contrat de Plan Etat-Région Languedoc-Rousillon; Insitut Pneumologique d'Aquitaine; the Swiss Federal Institute for Forest, Snow and Landscape Research; the canton governments of Aargan, Basel-Stadt, Basel-Land, Geneva, Luzern, Ticino, Valais and Zürich; Glaxo France; The Swiss Federal Office of Roads and Transport; Ministère de la Santé; Astma- och Allergiförbundet; the British Lung Foundation; the UK National Asthma Campaign; Hjärt-Lungfonden; the UK Department of Health; The Landspitali University Hospital Research Fund; Hospital General Juan Ramón Jiménez; Medicinska Forskningsrådet; Fondo de Investigación Sanitaria grants 09/01511, 91/0016-060-05/E, 92/0319, 93/0393, PS09/00716, PS09/02185 and PS09/02457; Hospital General de Albacete; Italian Ministry of Health, Chiesi Farmaceutici SpA; Schweizerischer Nationalfonds zur Förderung der Wissenschaftlichen Forschung grants 3100-059302, 3200-042532, 3200-052720, 3247-065896, 3247BO-104283, 3247BO-104284, 3247BO-104288, 33CSCO-108796, 33CSCO-134276/1, 4026-028099 and 4026-28099; Forskningsrådet om Hälsa, Arbetsliv och Välfärd; Servicio Andaluz de Salud; Vegagerðin 
(The Icelandic Road Administration (ICERA)); Orkuveita Reykjavikur (Geothermal plant); Fonds Wetenschappelijk Onderzoek grant G.0.410.08.N.10; Regione del Veneto grant 381/05.93; ResMed Foundation; Sociedad Española de Neumología y Cirugía Torácica grant SEPAR 1001/2010; Forskningsrådet för Arbetsliv och Socialvetenskap; and Norges Forskningsråd grant 101422/310. Funding information for this article has been deposited with the Crossref Funder Registry.

\section{References}

1 To T, Stanojevic S, Moores G, et al. Global asthma prevalence in adults: findings from the cross-sectional world health survey. BMC Public Health 2012; 12: 204.

2 Garcia-Aymerich J, Varraso R, Anto JM, et al. Prospective study of physical activity and risk of asthma exacerbations in older women. Am J Respir Crit Care Med 2009; 179: 999-1003.

3 Franca-Pinto A, Mendes FA, de Carvalho-Pinto RM, et al. Aerobic training decreases bronchial hyperresponsiveness and systemic inflammation in patients with moderate or severe asthma: a randomised controlled trial. Thorax 2015; 70: 732-739.

4 Lucke J, Waters B, Hockey R, et al. Trends in women's risk factors and chronic conditions: findings from the Australian Longitudinal Study on Women's Health. Womens Health (Lond) 2007; 3: 423-432.

5 Russell MA, Janson C, Real FG, et al. Physical activity and asthma: a longitudinal and multi-country study. J Asthma 2017; 54: 938-945.

6 Benet M, Varraso R, Kauffmann F, et al. The effects of regular physical activity on adult-onset asthma incidence in women. Resp Med 2011; 105: 1104-1107.

7 Brumpton BM, Langhammer A, Ferreira MA, et al. Physical activity and incident asthma in adults: the HUNT Study, Norway. BMJ Open 2016; 6: e013856.

8 Burney PGJ, Luczynska C, Chinn S, et al. The European Community Respiratory Health Survey. Eur Respir J 1994; 7: 954-960.

9 Fuertes E, Carsin AE, Anto JM, et al. Leisure-time vigorous physical activity is associated with better lung function: the prospective ECRHS study. Thorax 2018; 73: 376-384.

10 Cassim R, Milanzi E, Koplin JJ, et al. Physical activity and asthma: cause or consequence? A bidirectional longitudinal analysis. J Epidemiol Community Health 2018; 72: 770-775.

11 Jarvis D, Newson R, Janson C, et al. Prevalence of asthma-like symptoms with ageing. Thorax 2018; 73: 37-48.

12 Global Initiative for Asthma. Global Strategy for Asthma Management and Prevention 2019. Available from: www.ginasthma.org. Date last accessed: 30 October 2019. Date last updated: June 2019.

13 The ISCO Team Department of Statistics. ISCO International Standard Classification of Occupations. www.ilo.org/ public/english/bureau/stat/isco/ Date last accessed: January 29, 2021. Date last updated: June 9, 2010.

14 Zou GY, Donner A. Extension of the modified Poisson regression model to prospective studies with correlated binary data. Stat Methods Med Res 2013; 22: 661-670.

15 Janson C, Malinovschi A, Amaral AFS, et al. Bronchodilator reversibility in asthma and COPD: findings from three large population studies. Eur Respir J 2019; 54: 1900561. 